\title{
Risk factors for malaria infection prevalence and household vector density between mass distribution campaigns of long-lasting insecticidal nets in North-western Tanzania
}

Jacklin F. Mosha ${ }^{1 *} \mathbb{D}$, Eliud Lukole1 ${ }^{1}$, J. Derek Charlwood ${ }^{2}$, Alexandra Wright ${ }^{2}$, Mark Rowland², Olivia Bullock², Alphaxard Manjurano ${ }^{1}$, William Kisinza ${ }^{4}$, Franklin W. Mosha ${ }^{3}$, Immo Kleinschmidt ${ }^{5}$ and Natacha Protopopoff ${ }^{2}$

\begin{abstract}
Background: Long-lasting insecticidal nets (LLINs) are the most widely deployed vector control intervention in subSaharan Africa to prevent malaria. Recent reports indicate selection of pyrethroid insecticide resistance is widespread in mosquito vectors. This paper explores risk factors associated with malaria infection prevalence and vector density between mass distribution campaigns, changes in net coverage, and loss of protection in an area of high pyrethroid resistance in Northwest Tanzania.
\end{abstract}

Methods: A cross sectional malaria survey of 3456 children was undertaken in 2014 in Muleba district, Kagera region west of Lake Victoria. Vector density was assessed using indoor light traps and outdoor tent traps. Anophelines were identified to species using PCR and tested for Plasmodium falciparum circumsporozoite protein. Logistic regression was used to identify household and environmental factors associated with malaria infection and regression binomial negative for vector density.

Results: LLIN use was $27.7 \%$. Only $16.9 \%$ of households had sufficient nets to cover all sleeping places. Malaria infection was independently associated with access to LLINs (OR: 0.57; 95\% CI 0.34-0.98). LLINs less than 2 years old were slightly more protective than older LLINs (53 vs 65\% prevalence of infection); however, there was no evidence that LLINs in good condition (hole index <65) were more protective than LLINs, which were more holed. Other risk factors for malaria infection were age, group, altitude and house construction quality. Independent risk factors for vector density were consistent with malaria outcomes and included altitude, wind, livestock, house quality, open eaves and LLIN usage. Indoor collections comprised 4.6\% Anopheles funestus and 95.4\% Anopheles gambiae of which 4.5\% were Anopheles arabiensis and $93.5 \%$ were Anopheles gambiae sensu stricto.

Conclusion: Three years after the mass distribution campaign and despite top-ups, LLIN usage had declined considerably. While children living in households with access to LLINs were at lower risk of malaria, infection prevalence remained high even among users of LLINs in good condition. While effort should be made to maintain high coverage between campaigns, distribution of standard pyrethroid-only LLINs appears insufficient to prevent malaria transmission in this area of intense pyrethroid resistance.

\footnotetext{
*Correspondence: jfmosha@yahoo.com

${ }^{1}$ National Institute for Medical Research, Mwanza Medical Research Centre, Mwanza, Tanzania

Full list of author information is available at the end of the article
}

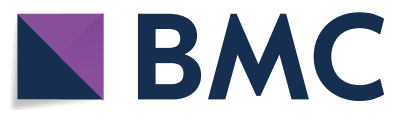

(c) The Author(s) 2020. This article is licensed under a Creative Commons Attribution 4.0 International License, which permits use, sharing, adaptation, distribution and reproduction in any medium or format, as long as you give appropriate credit to the original author(s) and the source, provide a link to the Creative Commons licence, and indicate if changes were made. The images or other third party material in this article are included in the article's Creative Commons licence, unless indicated otherwise in a credit line to the material. If material is not included in the article's Creative Commons licence and your intended use is not permitted by statutory regulation or exceeds the permitted use, you will need to obtain permission directly from the copyright holder. To view a copy of this licence, visit http://creativeco mmons.org/licenses/by/4.0/. The Creative Commons Public Domain Dedication waiver (http://creativecommons.org/publicdomain/ zero/1.0/) applies to the data made available in this article, unless otherwise stated in a credit line to the data. 
Keywords: Malaria, Llins, Effectiveness, Vectors, Tanzania

\section{Background}

Long-lasting insecticidal nets (LLINs) and indoor residual spraying (IRS) are the main vector control interventions deployed in sub-Saharan Africa to control malaria [1]. According to the World Health Organization (WHO), 69\% of the estimated 663 million malaria cases averted during the 15 years after the millennium were attributed to the use of LLINs. Despite the increase in LLIN access, in recent years malaria has increased in several sub-Saharan countries [2]. A similar trend has emerged in Tanzania with malaria prevalence in children under 5 years old decreasing from $18 \%$ in 2007 to 9\% in 2011 and then increasing to $14 \%$ in 2015 [3].

Insecticide-treated nets (ITNs) that required annual re-treatment were first distributed to pregnant women and infants through antenatal clinics in 2004. In 2008, LLINs that did not require re-treatment were distributed through mass campaigns targeting children under five years of age [4]. From 2011 onwards, distribution of LLINs was scaled up to cover the entire population, including adults, not previously reached. Approximately 18 million LLINs were distributed during this universal coverage campaign resulting in a net ownership (households owning at least one net) reaching $92 \%$ and usage of $72 \%$ [5].

ITNs are the most effective when usage is high to provide community protection [6]. The challenge, therefore, is to maintain high coverage between the mass distribution that occurs every 3-4 years [7]. Between universal coverage campaigns, LLIN coverage may be sustained by routine distributions through school and health facilities services $[8,9]$. The insecticidal effectiveness of WHO recommended LLINs are shown to last for at least three years of use. However, the physical durability of the textile may be shorter than 3 years depending on usage practices and wear-and-tear. LLINs that are still insecticidal may be discarded due to accumulation of holes long before the end of the net's insecticidal life [10].

The gains arising from increased usage of LLINs might also be undermined by the development of insecticide resistance among malaria vectors [11]. Resistance to pyrethroids is spreading across Africa, and has been reported in various districts of Tanzania [12]. While LLINs provided long term protection when mosquito vector populations in Tanzania were fully susceptible, effectiveness may become compromised in areas with high levels of pyrethroid resistance once LLINs deteriorate and develop holes [13, 14].
This study explored LLIN coverage indicators three years after the universal coverage campaign of 2011 and whether standard pyrethroid-only LLINs still provide protection against malaria vectors and infection prevalence in an area of intense pyrethroid resistance in Northwest Tanzania. It also explored other household and individual risk factors for malaria infection and vector density.

\section{Methods \\ Study area}

Cross sectional prevalence and entomological surveys were conducted during baseline of a cluster randomized controlled trial (RCT) assessing PBO LLINs and IRS with Actellic CS ${ }^{\circledR}$ (pirimiphos methyl) [15]. The study was conducted in 40 villages, divided in 48 clusters for the purpose of the RCT, in Muleba district ( $1^{\circ}$ $\left.45^{\prime} \mathrm{S} 31^{\circ} 40^{\prime} \mathrm{E}\right)$, Kagera Region, North West Tanzania [15]. The study area covers $944 \mathrm{~km}^{2}, 29,000$ households and an estimated population of 135,000 and is situated between 1100 and $1600 \mathrm{~m}$ above sea level [15]. There are two rainy seasons: in October-December with an average monthly rainfall of $160 \mathrm{~mm}$ and in MarchMay with an average monthly rainfall of $300 \mathrm{~mm}$ [16]. Malaria transmission occurs throughout the year and peaks after the rainy seasons. Malaria prevalence infection in children under 15 years of age in the study area was $37 \%$ in July 2011, higher than the overall prevalence of $23 \%$ in the district during the same period [17].

Anopheles gambiae sensu stricto (s.s.) resistant to pyrethroids and Anopheles arabiensis were the only vectors found in 2011 [18]. Resistance testing in the area showed mortality against pyrethroid of $8.8 \%$ for Anopheles gambiae and 54.5\% for Anopheles funestus and a resistance intensity of 38 fold for Anopheles gambiae sensu lato (s.l.) and 34 fold for Anopheles funestus compared to a susceptible mosquito strain [15].

Permethrin-treated LLINs (Olyset Net) were distributed through universal coverage campaign in 2011. After the campaign in 2011, net ownership was $90.8 \%$ and net usage was $55.7 \%$ [16]. Bendiocarb IRS was sprayed in 2011 and 2013, with house coverage over $90 \%$ in 2011 [19]. In the years following the 2011 campaign, additional LLINs were distributed though government clinics to protect pregnant women and children under 5 years of age. 


\section{Data collection}

Cross sectional malaria parasitaemia and household surveys The prevalence survey was carried out from September to October 2014 [15]. All households in the study area were mapped using hand-held Global Positioning System (GPS) units (Garmin Legend e-trex) and Expert GPS v3.8 (TopoGrafix) software. A total of 2880 households (60 households per cluster) were randomly selected amongst the census list to participate in a household survey. Up to three children aged 6 months to 14 years per house were randomly selected.

On obtaining household consent, a questionnaire was administered and data entered into a personal digital assistant (PDA, HP IPAQ 114 Classic Handheld) on number of residents, socio economic status, house construction and quality, education, access to and use of LLINs and other malaria preventive measures, and presence of livestock.

Selected children were given a coupon and asked to present the following day for parasitological testing. Plasmodium infection was assessed by a rapid diagnostic test (RDT) (CareStart RDTs; HRP2/pLDH, (pf/PAN), Diasys, Wokingham, UK) and haemoglobin levels measured using HemoCue Hb 201 + (Aktiebolaget Leo Diagnostics, USA). Results were initially recorded on paper forms and double entered into a digital database and checked for consistency.

In the same households selected for cross sectional survey, $20 \%$ of LLINs were inspected for assessment of physical condition and hole index determined according to WHO guidelines [20]. Nets were draped over a frame and holes counted, classified into categories of: less than $2 \mathrm{~cm}$ (size 1); 2-10 cm (size 2); > 10-25 cm (size 3) and $>25 \mathrm{~cm}$ (size 4), and proportional hole index (pHI) as an estimate of hole area was calculated. For purposes of analysis the LLINs were further categorized into three groups: good condition (pHI 0-64), moderately damaged (pHI 65-642) and badly damaged (pHI > 643) [21].

\section{Entomological monitoring}

From November 2014 to January 2015, indoor mosquito collections were conducted using CDC light traps in 14-21 randomly selected houses per cluster for one night only. The light traps were installed at the foot of a bed occupied by a family member sleeping under a LLIN. In addition, two or three furvela tent trap collections per cluster [22] were conducted for one night to assess outdoor density. They were placed near to houses selected for indoor light trap collections. Further information on house structure, livestock, and LLINs access and usage was collected. All mosquitoes collected were morphologically identified to species [23]. Up to 20 Anopheline mosquitoes per house were subsequently tested for Plasmodium falciparum circumsporozoite protein (Pf-CSP) using ELISA [24]. A sub-sample of An. gambiae s.l. was tested using real time PCR Taq Man assay to distinguish between the two sibling species An. gambiae s.s. and $A n$. arabiensis [25]. Species composition of Anopheles funestus complex was determined using conventional PCR [26].

\section{Statistical analysis}

Statistical analysis was performed using STATA (version 12, College Station, TX, USA). Random effects logistic regression models were used to determine possible risk factors for malaria infection determined by RDT in children $0.5-14$ years old adjusting for correlation of malaria infection within clusters.

Potential household and personal risk factors were explored: age, gender, individual net use, education of household head, social economic status (SES), quality of house construction and presence of open eaves, number of people per sleeping room (a proxy for crowding), LLIN ownership and access, indoor residual spraying (IRS) in 2013, presence and proximity of livestock.

Variables were cleaned and coded and those which were nonlinearly related to the outcome were categorized. Variables were created for improved housing structure, individual net use, household net access, household crowding and social economic status, detail of all variables is indicated in Table 1.

All variables were analysed individually for an association with malaria infection (outcome) using a logistic regression that included village and household as random effects to account for correlation within individual village clusters and households. All potential risk factors showing evidence for a possible association with malaria infection $(\mathrm{p}<0.1)$ were included in the preliminary main effect multivariate logistic regression model. A forward stepwise method was used, retaining any risk factors showing an association (LRT test $\mathrm{p}<0.05$ ). No a priori interaction terms were identified. Multi-collinearity was assessed for by removing parameters one by one from the model and examining the standard errors of the remaining parameters. If this caused the standard error of one of the remaining parameters to change by $>10 \%$ this was defined as multi-collinearity and one of the parameters removed.

A similar approach was adopted to assess risk factors for indoor vector density. Because vector density count data was skewed and often over dispersed, a negative binomial regression analysis was used. The model estimated a density rate ratio (DRR) as the measure of effect. Univariate regression of each risk factor was performed 
Table 1 Definition of variables

\begin{tabular}{|c|c|}
\hline Indicators & Description \\
\hline Age & Age was categorized into three groups: $0.5-1$ year, $2-4$ years and $5-14$ years \\
\hline Altitude & $\begin{array}{l}\text { Altitude (metres) was categorized into three groups with the following cutoff Low altitude ranging (1128- } \\
\text { 1264), Medium altitude ranging (1265-1352) High altitude ranging (1353-1654) }\end{array}$ \\
\hline Social economic status & $\begin{array}{l}\text { SES was created as a weighted sum of data on household possessions and utilities, using principal compo- } \\
\text { nents analysis and divided into tertiles }\end{array}$ \\
\hline Improved housing structure & $\begin{array}{l}\text { Is a binary variable where houses are coded as 'yes' if they have at least one of the following intact ceiling, } \\
\text { brick walls, plastered walls, full cement floors and iron roofs }\end{array}$ \\
\hline Household crowding & $\begin{array}{l}\text { Number of people sleeping per room. Number of sleepers per room was dichotomized into groups with } 1 \text {, } \\
\text { and }>1 \text { person sleeping in the room }\end{array}$ \\
\hline Eaves of the house & Binary variable 'open' if household has open eaves or 'closed' if household has no open eaves \\
\hline LLINs'ownership & Binary variable 'yes' if household owns at least one LLIN \\
\hline Individual LLIN condition & $\begin{array}{l}\text { Physical condition of the net used by sleeper. The variable is categorized in. 1/ good condition net (PHI 0-64). } \\
2 \text { / moderate condition net ( } \mathrm{PHI} 65-642) \text { and } 3 \text { / torn net }(\mathrm{PHI}>643)\end{array}$ \\
\hline Individual LLIN usage & This is a binary variable indicating whether individual is sleeping under a net or not \\
\hline Household net access & $\begin{array}{l}\text { Binary variable'yes' if household owns enough net to cover every sleeping place. Which is number of LLINs } \\
\text { owned (regardless if used or not) divided by the number of sleeping places }\end{array}$ \\
\hline Indoor residual spraying (IRS) & Binary variable 'yes' if household was sprayed in 2013 \\
\hline Livestock present & Binary variable 'yes' if livestock are owned \\
\hline Animal kept inside the house & Binary variable 'yes' if animals are sleeping inside the household, this included goats, sheep and cows \\
\hline Level of education of head of household & Binary variable 'yes' if the head of household has at least completed primary education \\
\hline Moderate to severe Anaemia & Defined as haemoglobin $<8 \mathrm{~g} / \mathrm{dL}$ \\
\hline
\end{tabular}

initially and the forward step-wise method was used to build a multivariate model.

\section{Results}

\section{Household and study participants}

The total number of households which were selected to participate in the baseline survey was 2880 . Of these $2270(78.8 \%)$ consented to participate, $276(9.6 \%)$ failed to meet the inclusion criteria (no children $<15$ years), 13 $(0.5 \%)$ refused and $11.1 \%$ were excluded for other reasons (Fig. 1). Of the 6918 children aged between 0.5 and 14 years, 4388 (63.4\%) were selected for inclusion and of these 3871 participated in the clinical survey, 10 children had missing RDT results and 517 (11.8\%) children did not turn up for testing. Therefore, of the total children selected 3861 (88\%) were included in the analysis (Fig. 1).

Almost all nets which were used were LLINs (96.8\%). The proportion of individuals who reported using a net the night before was $27.1 \%$. The proportion of nets declared to be less than 2 years old was $37.1 \%$, those $2-3$ years old was $31.3 \%$ and those over 3 years old were $31.4 \%$. Many of the nets had been received via clinicbased distribution during the period since the last UCC. Only $26 \%$ of individuals slept under nets of good condition, $35 \%$ slept under nets of moderate condition and $38 \%$ under nets which were badly torn. Net access was very low; only $16.9 \%$ of individuals were residing in households with enough nets to cover all sleeping places.
About $25.9 \%$ of the households reported to be sprayed with insecticide in the year before (Table 2).

Of the 1008 households selected for indoor entomological collection 770 participated, and of 144 selected for outdoor collection 120 participated (Fig. 1). Altitude of study households ranged from 1128 to $1654 \mathrm{~m}$ above sea level. Around $76.8 \%$ of households were constructed with mud walls and floors, and $61.2 \%$ of houses had open eaves. Most households (94.3\%) relied on farming or fishing and selling cash crops for income. Most individuals came from houses with livestock (73.1\%) and 33.5\% of these kept animals inside the household. $73.3 \%$ of heads of households had attended primary school (Table 3).

\section{Plasmodium infection prevalence and risk factors for malaria infection}

Overall malaria infection prevalence (all Plasmodium species) was $64.8 \%$ (95\% CI 61.8-67.8) in children aged 6 months to 14 years old. The prevalence of clinical malaria, defined as fever (ear temperature, $\geq 37.5{ }^{\circ} \mathrm{C}$ ) and any Plasmodium infection by RDT was $6.8 \%$ (95\% CI $5.5-8.1$ ). Only $2.9 \%$ (114) of tested children had fever and among those who had fever $86 \%$ had a positive test result. The prevalence of moderate or severe anaemia (haemoglobin $<8 \mathrm{~g} / \mathrm{dL}$ - see Table 1 for variables' definitions) in children under five was $19.5 \%$ (95\% CI 17.9-21.4). Among anaemic children 88.9\% (95\% CI 85.5-92.2) had malaria infection. The odds of moderate-severe anaemia 


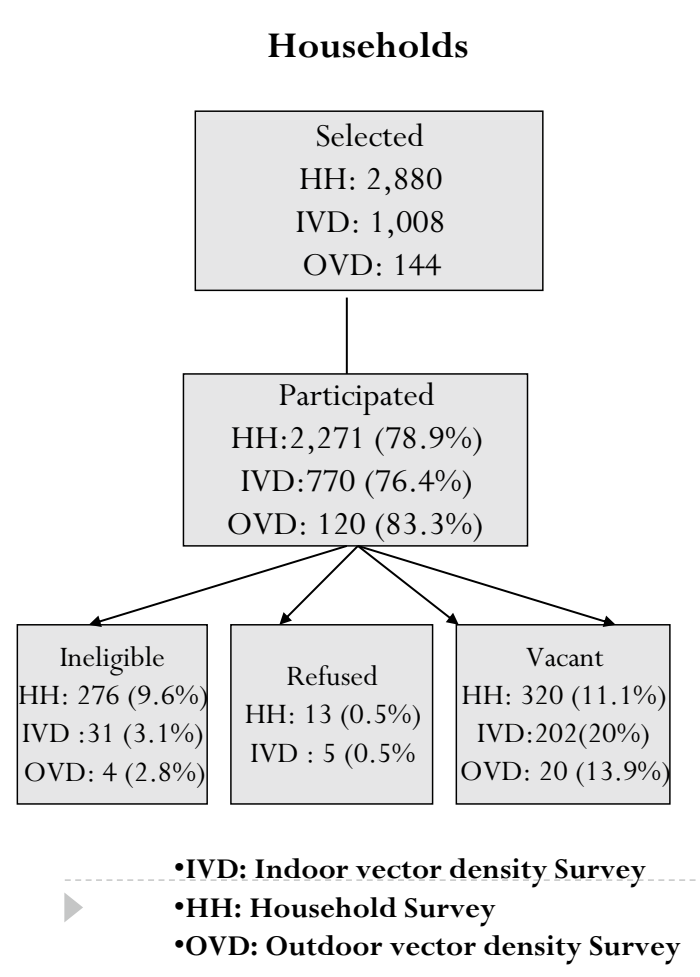

\section{Individuals Clinical Survey}

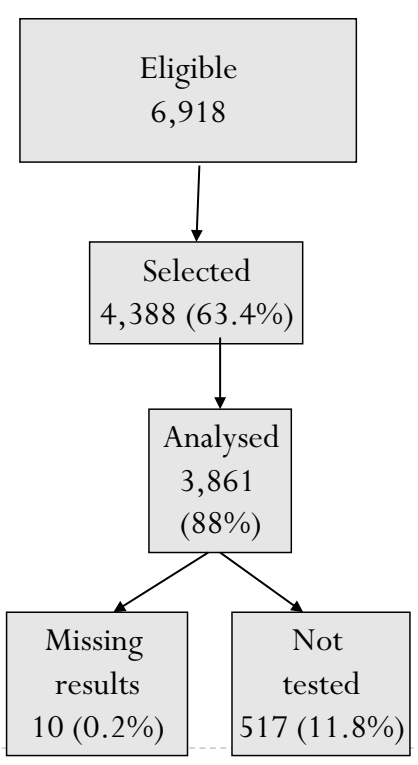

-HH: Household Survey

Fig. 1 Study profile for household, individual selection and entomological monitoring

was six times higher if the child had malaria infection (OR 6.2, 95\% CI 5.0-7.6).

In the univariate analysis the odds of malaria infection was lower with living at higher altitudes, in children in younger age groups, with better education, improved house structure, closed eaves, greater wealth, presence of livestock, net ownership, adequate access to LLINs, use of LLINs and with newer LLINs (Table 2).

In the multivariate model, malaria infection was independently associated with altitude, age, quality of housing structure, and adequate net access per sleeping place. The odds of malaria infection decreased with increasing altitude. Individuals living at high altitude had much lower odds of malaria infection compared to those who were living at lower altitude (OR $0.1895 \%$ CI 0.13-0.26).

The odds of malaria infection increased with age, the oldest group being the most at risk (OR 3.82, 95\% CI 1.89-7.72). Children living in improved housing structure had lower odds of malaria infection compared to those who were living in unimproved housing (OR 0.27, 95\% CI 0.13-0.54). Individuals living in houses with an open eaves showed a strong association with malaria infection compared to those who were living in houses with closed eave gaps (OR 0.59; 95\% CI 0.51-0.69).

Individuals who were living in households with adequate net access per sleeping place were better protected from malaria infection (59 vs 66\%, OR 0.57; 95\% CI 0.34$0.98, \mathrm{p}=0.042$ ). Age of LLINs was also significant, with only LLINs less than two years of age showing evidence of protection ( 53 vs $65 \%, \mathrm{p}=0.004$ ). LLINs' usage was not associated with malaria prevalence in the multivariate analysis. There was no association between malaria protection and the hole index of LLINs over the WHO LLIN categories of good condition (32\% infection prevalence, $49 / 154)$ to 'unserviceable' condition $(36 \%, 80 / 221)$.

None of the other factors (gender, wealth, livestock, household head education, IRS spraying 18 months earlier, household owning at least one LLIN, and usage of LLINs of different physical conditions) were associated with malaria infection once adjusted for the other factors in the model.

\section{Mosquito fauna and risk factors for vector density}

A total of 29,401 and 2668 mosquitoes were collected in 770 indoor light trap collections and in 120 outdoor tent trap collections respectively. Anophelines comprised 64\% of the indoor collections and $57 \%$ of the outdoor collections. Mean vector density per collection night was 24.5 indoors and 12.7 outdoors. Of the Anophelines collected 4.6\% were identified as An. funestus s.l. and the remaining were An. gambiae s.l.. The 969 An. gambiae s.l. were identified to species by PCR, $93.5 \%$ were An. gambiae 
Table 2 Factors associated with malaria infection in the univariate and multivariate analysis

\begin{tabular}{|c|c|c|c|c|c|c|c|c|}
\hline & \multirow{2}{*}{$\begin{array}{l}\text { Number } \\
\text { of children }\end{array}$} & \multirow{2}{*}{$\begin{array}{l}\% \text { with malaria } \\
\text { infection (\%) }\end{array}$} & \multicolumn{3}{|c|}{ Univariate } & \multicolumn{3}{|c|}{ Multivariate } \\
\hline & & & OR & $96 \% \mathrm{Cl}$ & $p$-value & $\overline{\mathrm{OR}}$ & $96 \% \mathrm{Cl}$ & $p$-value \\
\hline \multicolumn{9}{|l|}{ Altitude (metres) } \\
\hline Low (1128-1264) & 1300 & 74.7 & 1 & & & & & \\
\hline Medium (1265-1352) & 1291 & 68.1 & 0.38 & $0.28-0.50$ & 0.001 & 0.78 & $0.42-1.43$ & 0.416 \\
\hline High (1353-1654) & 1266 & 51.0 & 0.14 & $0.10-0.20$ & 0.001 & 0.27 & $0.14-0.55$ & $<0.001$ \\
\hline \multicolumn{9}{|l|}{ Age } \\
\hline$<1$ year & 384 & 50.5 & 1 & & & & & \\
\hline $2-4$ years & 1062 & 63.0 & 1.86 & $1.44-2.41$ & $<0.001$ & 2.59 & $1.31-5.11$ & 0.006 \\
\hline $5-14$ years & 2414 & 67.7 & 2.52 & $1.99-3.20$ & $<0.001$ & 3.82 & $1.89-7.72$ & $<0.001$ \\
\hline \multicolumn{9}{|l|}{ Improved housing structure } \\
\hline No & 589 & 76.9 & 1 & & & 1 & & \\
\hline Yes & 3272 & 62.5 & 0.32 & $0.22-0.48$ & $<0.001$ & 0.27 & $0.13-0.54$ & $<0.001$ \\
\hline \multicolumn{9}{|l|}{ Socio economic status } \\
\hline Poorest & 1261 & 72.6 & 1 & & & 1 & & \\
\hline Middle & 1264 & 64.3 & 0.72 & $0.59-0.86$ & 0.001 & 0.98 & $0.51-1.89$ & 0.961 \\
\hline Least poor & 1258 & 57.6 & 0.50 & $0.42-0.60$ & $<0.001$ & 1.07 & $0.52-2.19$ & 0.862 \\
\hline \multicolumn{9}{|l|}{ Adequate access to LLINs } \\
\hline No & 3167 & 66.0 & 1 & & & 1 & & \\
\hline Yes & 643 & 58.8 & 0.68 & $0.57-0.83$ & $<0.001$ & 0.57 & $0.34-0.98$ & 0.042 \\
\hline \multicolumn{9}{|l|}{ Individual net age } \\
\hline$<2$ years & 350 & 52.9 & 1 & & & 1 & & \\
\hline $2-3$ years & 295 & 64.1 & 2.32 & $1.26-4.28$ & 0.007 & 1.89 & $1.01-3.53$ & 0.044 \\
\hline 4 years and more & 299 & 65.9 & 2.37 & $1.28-4.37$ & 0.006 & 1.90 & $1.02-3.58$ & 0.004 \\
\hline \multicolumn{9}{|l|}{ Sex } \\
\hline Male & 1869 & 66.0 & 1 & & & & & \\
\hline Female & 1870 & 63.4 & 0.87 & $0.75-1.01$ & 0.061 & & & \\
\hline \multicolumn{9}{|l|}{ Eaves of the house } \\
\hline Open & 2334 & 69.2 & 1 & & & & & \\
\hline Closed & 1478 & 57.9 & 0.59 & $0.51-0.69$ & $<0.001$ & & & \\
\hline \multicolumn{9}{|l|}{ Livestock present } \\
\hline No & 1026 & 67.6 & 1 & & & & & \\
\hline Yes & 2786 & 63.7 & 0.77 & $0.65-0.91$ & 0.002 & & & \\
\hline \multicolumn{9}{|l|}{ Animals kept inside the house } \\
\hline No & 1857 & 63.5 & 1 & & & & & \\
\hline Yes & 935 & 63.6 & 0.97 & $0.81-1.17$ & 0.757 & & & \\
\hline \multicolumn{9}{|l|}{ Head of household attended school } \\
\hline No & 1007 & 71.4 & 1 & & & & & \\
\hline Yes (any schooling) & 2791 & 62.4 & 0.74 & $0.62-0.88$ & 0.001 & & & \\
\hline \multicolumn{9}{|l|}{ IRS 18 months before } \\
\hline No & 2798 & 67.0 & 1 & & & & & \\
\hline Yes & 979 & 59.1 & 0.84 & $0.70-1.01$ & 0.06 & & & \\
\hline \multicolumn{9}{|l|}{ Household owns at least 1 net } \\
\hline No & 1165 & 69.1 & 1 & & & & & \\
\hline Yes & 2647 & 62.6 & 0.71 & $0.60-0.83$ & $<0.001$ & & & \\
\hline \multicolumn{9}{|l|}{ Individual usage of LLIN } \\
\hline Don't use net & 2276 & 66.4 & 1 & & & & & \\
\hline Use net & 1045 & 61.2 & 0.69 & $0.50-0.94$ & 0.018 & & & \\
\hline \multicolumn{9}{|l|}{ Individual LLIN condition } \\
\hline Use good condition net (PHI > 64) & 154 & 68.2 & 1 & & & & & \\
\hline
\end{tabular}


Table 2 (continued)

\begin{tabular}{|c|c|c|c|c|c|c|c|c|}
\hline & \multirow{2}{*}{$\begin{array}{l}\text { Number } \\
\text { of children }\end{array}$} & \multirow{2}{*}{$\begin{array}{l}\% \text { with malaria } \\
\text { infection (\%) }\end{array}$} & \multicolumn{3}{|c|}{ Univariate } & \multicolumn{3}{|c|}{ Multivariate } \\
\hline & & & OR & $96 \% \mathrm{Cl}$ & p-value & OR & $96 \% \mathrm{Cl}$ & $p$-value \\
\hline Use moderate condition net (PHI 65-642) & 206 & 61.7 & 0.65 & $0.28-1.49$ & 0.307 & & & \\
\hline Use torn net (PHI > 643) & 221 & 63.8 & 0.77 & $0.34-1.77$ & 0.544 & & & \\
\hline
\end{tabular}

Table 3 Risk factors associated with vector density in the univariate and multivariate models

\begin{tabular}{|c|c|c|c|c|c|c|c|c|}
\hline & \multirow[t]{2}{*}{ Number of $\mathrm{HH}$} & \multirow{2}{*}{$\begin{array}{l}\text { Indoor vector } \\
\text { density }\end{array}$} & \multicolumn{3}{|c|}{ Univariate } & \multicolumn{3}{|c|}{ Multivariate } \\
\hline & & & IRR & $96 \% \mathrm{Cl}$ & $p$-value & IRR & $96 \% \mathrm{Cl}$ & p-value \\
\hline \multicolumn{9}{|l|}{ Altitude (metres) } \\
\hline $1133-1242$ & 192 & 63.2 & 1 & & & 1 & & \\
\hline $1243-1302$ & 191 & 22.6 & 0.63 & $0.49-0.80$ & $<0.001$ & 0.58 & $0.46-0.74$ & $<0.001$ \\
\hline $1303-1373$ & 192 & 6.8 & 0.51 & $0.40-0.66$ & $<0.001$ & 0.44 & $0.33-0.58$ & $<0.001$ \\
\hline $1374-1651$ & 191 & 5.7 & 0.39 & $0.29-0.51$ & $<0.001$ & 0.35 & $0.27-0.46$ & $<0.001$ \\
\hline \multicolumn{9}{|l|}{ Wind during collection } \\
\hline None/light & 433 & 28.2 & 1 & & & 1 & & \\
\hline Moderate/strong & 335 & 19.9 & 0.77 & $0.64-0.93$ & 0.007 & 0.69 & $0.57-0.83$ & $<0.001$ \\
\hline \multicolumn{9}{|l|}{ Livestock } \\
\hline No & 267 & 17.5 & 1 & & & 1 & & \\
\hline Yes & 502 & 28.3 & 1.13 & $0.95-1.35$ & 0.159 & 1.35 & $1.12-1.62$ & 0.001 \\
\hline \multicolumn{9}{|c|}{ Improved housing structure } \\
\hline No & 579 & 29.3 & 1 & & & 1 & & \\
\hline Yes & 183 & 10.1 & 0.78 & $0.63-0.95$ & 0.016 & 0.83 & $0.67-1.02$ & 0.072 \\
\hline \multicolumn{9}{|c|}{ Household using at least 1 LLIN } \\
\hline No & 264 & 22.9 & 1 & & & 1 & & \\
\hline Yes & 505 & 25.4 & 0.79 & $0.66-0.93$ & 0.006 & 0.78 & $0.66-0.92$ & 0.004 \\
\hline Number of rooms & 770 & 24.9 & 0.89 & $0.84-095$ & $<0.001$ & 0.90 & $0.84-0.96$ & 0.001 \\
\hline \multicolumn{9}{|c|}{ Household cooks inside the house } \\
\hline No & 620 & 23.3 & 1 & & & & & \\
\hline Yes & 149 & 29.6 & 1.31 & $1.07-1.59$ & 0.010 & & & \\
\hline $\begin{array}{l}\text { Total time house has } \\
\text { been sprayed }\end{array}$ & 756 & 24.9 & 0.94 & $0.90-0.99$ & 0.011 & & & \\
\hline \multicolumn{9}{|c|}{ Animal inside the house } \\
\hline No & 308 & 29.2 & 1 & & & & & \\
\hline Yes & 196 & 26.5 & 1.01 & $0.82-1.25$ & 0.933 & & & \\
\hline \multicolumn{9}{|l|}{ Rain during collection } \\
\hline None & 435 & 23.7 & 1 & & & & & \\
\hline Light & 164 & 37.1 & 0.98 & $0.78-1.24$ & 0.894 & & & \\
\hline Heavy & 169 & 14.5 & 1.15 & $0.92-1.44$ & 0.234 & & & \\
\hline \multicolumn{9}{|l|}{ Eaves of the house } \\
\hline Closed & 324 & 22.9 & 1 & & & & & \\
\hline Open & 445 & 25.7 & 1.17 & $0.99-1.38$ & 0.071 & & & \\
\hline
\end{tabular}

s.s. , $4.5 \%$ were An. arabiensis, and $2.2 \%$ did not amplify. There was no evidence of difference in ratio of An. gambiae s.s. to $A n$. arabiensis between indoor and outdoor collections $\left(\mathrm{X}^{2} 3.5, \mathrm{p}=0.18\right)$. Of the 289 An. funestus identified by PCR $81.7 \%$ were An. funestus s.s., $15.6 \%$
Anopheles leesoni, 1.0\% Anopheles parensis and 1.7\% did not amplify. A subsample of 4311 specimens was tested for CSP. The sporozoite rate was $4.7 \%$. Both An. funestus and An. gambiae s.s. were found positive for CSP. The entomological inoculation rate was 0.34 (95\% CI 
0.20-0.49) infectious bites per person-night during the period of collection, and this rate varied from 0 to 2.7 between village clusters.

Altitude of households selected during the entomology survey ranged from 1133 to $1651 \mathrm{~m}$, with a mean of $1303 \mathrm{~m}$. It rained during $43.4 \%$ of collections and the wind was moderate or strong during $43.6 \%$ of collections. $34.7 \%$ of households did not have animals. For those that owned animals, 39\% kept them indoor. 50\% of families had poorly constructed houses and $24 \%$ had improved houses. $57.9 \%$ of houses had open eaves. The median number of rooms was 5 per house and median household size was 5 persons. Only $19.4 \%$ of families cooked inside the house. Houses had been sprayed 3 times since the first IRS campaign in 2007. An average of $65.7 \%$ of households were using at least one LLINs.

The univariate analyses showed evidence for negative associations between vector density and improved housing, number of rooms, households using at least one LLINs and number of times the house had been sprayed. Cooking inside the house was associated with higher vector densities. Altitude above $1242 \mathrm{~m}$ was associated with a decreased risk of indoor vectors, whereas light wind or no wind during collection was associated with increased risk.

House structure had an IRR of 0.75 (95\% CI 0.60-0.90), indicating a $25 \%$ decreased risk of vector exposure in improved housing. Using at least one LLIN in the household and several times sprayed was associated with reduced vector density. There was no evidence of association with rain during collection night, open eaves or animals present inside the house.

The multivariate model retained five risk factors as significant: altitude, wind during collection, presence of livestock, house construction and LLINs' usage. Number of rooms, showed co-linearity with house construction and, was therefore removed from the model. There was strong association with vector density, altitude and wind. Vector density was negatively associated with increasing altitude, being $65 \%$ less at the higher altitudes (above $1353 \mathrm{~m}$ ) and with nights with moderate or strong winds. Improved housing structure was associated with reduced vector density whereas presence of livestock was associated with higher vector density. Net usage was associated with density after adjusting for other factors. The variables that showed no association with vector density in the multivariate model were: history of IRS, cooking indoors and presence of open eaves.

\section{Discussion}

This study investigated the effects of LLINs three years after the last universal coverage campaign of 2011 in an area of intense pyrethroid resistance in Northwest
Tanzania. The aim of the study was to explore the effects of net coverage and deterioration as well as other household and individual risk factors associated to malaria infection and vector density. At the time of the study many of the original LLINs had developed holes or been replaced by newer ones. Malaria prevalence was over $60 \%$ in the study area in 2014 , while the estimated number of infective bites per day was 0.34 . These rates were much higher than the rates observed in the same area in 2011 shortly after the campaign [17]. An increase in malaria infection was also observed in other regions during the same period. After the initial decrease in malaria infection to $9 \%$ (ranging 1-25\%), malaria prevalence increased to $14 \%$ (ranging from 1 to $41 \%$ ) across seven regions of the country by 2014 [3]. Various factors may have contributed to the rebound of malaria in the study area: these include reduced LLIN effectiveness caused by increasing insecticide resistance combined with deterioration of the LLINs' physical condition, and reduced coverage and usage of LLINs.

LLIN ownership had decreased from $90.8 \%$ after the universal coverage campaign of 2011 to $69 \%$ in 2014 [16] and usage from 55.7 to $27.7 \%$ during the same period. While good household access to LLINs and self-reported individual LLIN use were both associated with reduced risk of malaria infection in the risk factor analysis, the reduction in LLIN coverage and usage in the years after the campaign would have contributed to the observed increase in malaria prevalence in 2014. The reported reasons for not using LLINs included: LLINs becoming torn over time and the poor access to new LLINs, which is consistent with findings from other studies [27]. Even in households with adequate access to LLINs malaria infection prevalence was still 59\%, indicating loss of effectiveness of LLINs due to other reasons.

In the present study, access to LLINs was associated with malaria protection in the multivariate analysis whereas usage was not. This is not the first community study showing that net use is not associated with malaria. Net use last night is based on self-reporting by household members while access and ownership is observed and may be more reliable net coverage indicators [28, 29].

About $53 \%$ of the nets which were still in use had holes and around $35 \%$ of the nets were badly torn ( $\mathrm{pHI}>643$ ). Previous studies have indicated that personal and community effectiveness of LLINs declines over time due to factors such as net coverage, ageing of nets, net damage and insecticide resistance $[13,14]$. Protection against highly resistant mosquitoes is reduced when LLINs develop holes because such mosquitoes are more able to penetrate the net via the holes, bite and blood feed [13, 14]. However, the level of protection was not associated with hole index category. It is possible the sample size 
was underpowered; only 581 (15\%) of the 3861 children tested for malaria had their nets assessed for hole index. Nevertheless, even a small degree of holing might be sufficient for a LLIN to lose its capacity to protect when pyrethroid resistance reaches high frequency and intensity $[13,14]$. There was significantly greater protection from malaria among users of LLINs less than two years of age; such nets would have fewer holes, higher concentrations of pyrethroid and were potentially more repellent to insecticide resistant mosquitoes. Once nets are more than two years of age they lose some capacity to protect against mosquitoes that are highly resistant. This observation should be kept in perspective; the actual difference in infection prevalence was between $53 \%$ in users of LLINs $<2$ years old and $64 \%$ in LLINs $>2$ years old. Standard LLINs were simply no longer adequately protective against this highly resistant vector population.

Other main risk factors for malaria infection prevalence in children 6 months to 14 years included living in area of lower altitude, in poorly constructed houses and with open eaves, being 5-14 years old, and coming from a lower socio-economic category. The same risk factors are also associated with higher vector density. These findings are consistent with other studies [30]. Some studies have reported an increased parasitaemia in children living at low altitudes compared to those who lived at high altitudes [31]. High altitudes are associated with lower temperatures, which have an impact on growth of mosquito larvae and therefore mosquito abundance [32]. Lower temperature increases the interval between biting/ feeding cycles and also slows the rate of malaria parasite development within the mosquitoes.

The observed increased risk of malaria infection in people living in poor housing is consistent with previous studies [33, 34]. Living in improved housing was also associated with reduced vector density. A recent systematic review and meta-analysis found that the odds of malaria infection was $47 \%$ lower among residents of modern houses compared to traditional houses [34]. House designs with open eaves and unscreened windows have been associated with increased risk for malaria infection, as a gap in the eaves is an entry point for malaria vectors [35].

Increased risk of malaria infection in older children (the 5-14 year age group) compared to younger children seen in this study is a trend which has been observed in other studies conducted elsewhere in Tanzania [36]. Older children have higher exposure to mosquito bites compared to younger age groups as they may tend to sleep later and less likely to use LLINs in some studies and places [37]. In addition, due to the acquired antimalarial immunity in older children, most have persistent asymptomatic malaria infections that are less likely to be treated, unlike younger children [38].

Households that own livestock had higher vector density, but this did not translate in increased malaria infection prevalence when adjusted for other co-variates. This suggests that livestock may attract Anopheles, but did not lead to an increase in human biting rate. The impact that livestock have on malaria and vector density is complex. Some studies indicate that livestock provides zooprophylatic protection [39], while other studies showed that livestock increases risk [40]. It depends on how the livestock are deployed within the household compound relative to humans and the anthrophilic/zoophilic plasticity of the vector species. Further study of vector composition between household with or without livestock would be required to better understand the difference in the present study.

The study has some limitations. The prevalence cross sectional survey was carried out before the entomological collections potentially affecting level of net coverage in the households and therefore comparability. However similar risk factors were associated with both outcomes showing that this one-month time lag may not have affected the findings of the study. Net usage assessment was based on self-reporting by household members and might not be reliable which could explain the lack of association between usage and malaria infection prevalence.

\section{Conclusion}

Three years after the universal coverage campaign LLIN usage had decreased considerably despite distribution of new LLINs in the interim. Children living in households with full access to LLINs per sleeping place were at lower risk of malaria; however, malaria prevalence in this group remained high. Standard pyrethroid-only LLINs were no longer sufficiently protective even when in good condition and relatively new. More efforts should be made to maintain high coverage of more effective types of LLIN between campaigns.

\footnotetext{
Acknowledgements

The authors express their sincere thanks to all colleagues and staff from Kilimanjaro Christian Medical University College in Muleba and Moshi, and from the National Institute of Medical Research Mwanza involved in the project for their hard work. We acknowledge the assistance provided by staff of the Muleba District Office, the village and hamlet leaders. We thank, NMCP, USAID/ PMl for their support.
}

\section{Authors' contributions}

NP, FWM, IK, MR, JFM designed the study. JFM, NP EL, JDC, AW, AM implemented the study. JFM and NP analysed the data. JFM, NP, IK, MR interpreted the data. JFM and NP wrote the first draft of the manuscript. MR and IK critically revised the manuscript for important content. EL, JDC, AW, AM, FWM, WK, IK, and MR in particular revised the manuscript. All authors read and approved the final manuscript. 


\section{Funding}

This study was funded under the Joint Global Health Trials Scheme by DFID,

Medical Research Council and, Wellcome Trust (Grant Ref: MR/L004437/).

\section{Availability of data and materials}

The datasets used and/or analysed during the current study are available from the corresponding author on reasonable request.

\section{Ethical approval and consent to participants}

The trial was approved by the ethics review committees of the Kilimanjaro Christian Medical College, the National Institute for Medical Research Tanzania and the London School of Hygiene and Tropical Medicine. Written informed consent was obtained from all participants or the parents/guardians if under 15 years old.

\section{Consent for publication}

Not applicable.

\section{Competing interests}

The authors declare that they have no competing interests.

\section{Author details}

${ }^{1}$ National Institute for Medical Research, Mwanza Medical Research Centre, Mwanza, Tanzania. ${ }^{2}$ Department of Disease Control, London School of Hygiene and Tropical Medicine, London, UK. ${ }^{3}$ Kilimanjaro Christian Medical University College, Moshi, Tanzania. ${ }^{4}$ Amani Medical Research Centre, National Institute for Medical Research, Muheza, Tanzania. ${ }^{5}$ MRC Tropical Epidemiology Group, Department of Infectious Disease Epidemiology, London School of Hygiene and Tropical Medicine, London, UK.

Received: 2 April 2020 Accepted: 10 August 2020

Published online: 20 August 2020

\section{References}

1. Bhatt S, Weiss DJ, Cameron E, Bisanzio D, Mappin B, Dalrymple U, et al. The effect of malaria control on Plasmodium falciparum in Africa between 2000 and 2015. Nature. 2015;526:207-11.

2. WHO. World Malaria Report 2018. Geneva: World Health Organization; 2018.

3. National Bureau of Statistics. Demographic and health survey and malaria indicator survey 2015-2016. Tanzania: Dar Es Salaam; 2016.

4. Bonner K, Mwita A, McElroy PD, Omari S, Mzava A, Lengeler C, et al. Design, implementation and evaluation of a national campaign to distribute nine million free LLINs to children under five years of age in Tanzania. Malar J. 2011;10:73.

5. Renggli S, Mandike R, Kramer K, Patrick F, Brown NJ, McElroy PD, et al. Design, implementation and evaluation of a national campaign to deliver 18 million free long-lasting insecticidal nets to uncovered sleeping spaces in Tanzania. Malar J. 2013;12:85.

6. Levitz L, Janko M, Mwandagalirwa K, Thwai KL, Likwela JL, Tshefu AK, et al. Effect of individual and community-level bed net usage on malaria prevalence among under-fives in the Democratic Republic of Congo. Malar J. 2018;17:39.

7. Koenker HM, Yukich JO, Mkindi A, Mandike R, Brown N, Kilian A, Lengeler C. Analysing and recommending options for maintaining universal coverage with long-lasting insecticidal nets: the case of Tanzania in 2011. Malar J. 2013;12:150.

8. Kramer K, Mandike R, Nathan R, Mohamed A, Lynch M, Brown N, et al. Effectiveness and equity of the Tanzania National Voucher Scheme for mosquito nets over 10 years of implementation. Malar J. 2017;16:255.

9. Acosta A, Obi E, Ato Selby R, Ugot I, Lynch M, Maire M, et al. Design, implementation, and evaluation of a school insecticide-treated net distribution program in Cross River State. Nigeria Glob Health Sci Pract. 2018;6:272-87.

10. Gnanguenon V, Azondekon R, Oke-Agbo F, Beach R, Akogbeto M. Durability assessment results suggest a serviceable life of two, rather than three, years for the current long-lasting insecticidal (mosquito) net (LLIN) intervention in Benin. BMC Infect Dis. 2014;14:69.
11. Ranson H, N'Guessan R, Lines J, Moiroux N, Nkuni Z, Corbel V. Pyrethroid resistance in African anopheline mosquitoes: what are the implications for malaria control? Trends Parasitol. 2011;27:91-8.

12. Kabula B, Tungu P, Malima R, Rowland M, Minja J, Wililo R, et al. Distribution and spread of pyrethroid and DDT resistance among the Anopheles gambiae complex in Tanzania. Med Vet Entomol. 2014;28:244-52.

13. Ochomo EO, Bayoh NM, Walker ED, Abongo BO, Ombok MO, Ouma C, et al. The efficacy of long-lasting nets with declining physical integrity may be compromised in areas with high levels of pyrethroid resistance. Malar J. 2013;12:368.

14. Asidi A, N'Guessan R, Akogbeto M, Curtis C, Rowland M. Loss of household protection from use of insecticide-treated nets against pyrethroidresistant mosquitoes. Benin Emerg Infect Dis. 2012;18:1101-6.

15. Protopopoff N, Mosha JF, Lukole E, Charlwood JD, Wright A, Mwalimu $C D$, et al. Effectiveness of a long-lasting piperonyl butoxide-treated insecticidal net and indoor residual spray interventions, separately and together, against malaria transmitted by pyrethroid-resistant mosquitoes: a cluster, randomised controlled, two-by-two factorial design trial. Lancet. 2018;391:1577-88.

16. West PA, Protopopoff N, Rowland MW, Kirby MJ, Oxborough RM, Mosha FW, et al. Evaluation of a national universal coverage campaign of longlasting insecticidal nets in a rural district in north-west Tanzania. Malar J. 2012;11:273.

17. West PA, Protopopoff N, Wright A, Kivaju Z, Tigererwa R, Mosha FW, et al. Enhanced protection against malaria by indoor residual spraying in addition to insecticide treated nets: is it dependent on transmission intensity or net usage? PLoS ONE. 2015;10:e0115661.

18. Protopopoff N, Matowo J, Malima R, Kavishe R, Kaaya R, Wright A, et al. High level of resistance in the mosquito Anopheles gambiae to pyrethroid insecticides and reduced susceptibility to bendiocarb in northwestern Tanzania. Malar J. 2013:12:149.

19. Protopopoff N, Wright A, West PA, Tigererwa R, Mosha FW, Kisinza W, et al. Combination of Insecticide treated nets and indoor residual spraying in Northern Tanzania provides additional reduction in vector population density and malaria transmission rates compared to insecticide treated nets alone: a randomised control trial. PLOS ONE. 2015;10:e0142671.

20. WHO. Guidelines for monitoring the durability of long-lasting insecticidal mosquito nets under operational conditions. Geneva: World Health Organization; 2011

21. WHO. Vector Control Technical Export Group report to MPAC September 2013: Estimating functional survival of long-lasting insecticidal nets from field data. Geneva: World Health Organization; 2013.

22. Charlwood JD, Rowland M, Protopopoff N, Le Clair C. The Furvela tent-trap Mk 1.1 for the collection of outdoor biting mosquitoes. PeerJ. 2017; $5:$ e3848

23. Gillies MT, Coetzee M. A supplement to the Anophelinae of Africa south of the Sahara (Afrotropical Region). Publ South Afr Inst Med Res. 1987;55:1-143

24. Wirtz RA, Zavala F, Charoenvit Y, Campbell GH, Burkot TR, Schneider I, et al. Comparative testing of monoclonal antibodies against Plasmodium falciparum sporozoites for ELISA development. Bull World Health Organ. 1987;65:39-45

25. Bass C, Williamson MS, Field LM. Development of a multiplex real-time PCR assay for identification of members of the Anopheles gambiae species complex. Acta Trop. 2008;107:50-3.

26. Koekemoer LL, Kamau L, Hunt RH, Coetzee M. A cocktail polymerase chain reaction assay to identify members of the Anopheles funestus (Diptera: Culicidae) group. Am J Trop Med Hyg. 2002;66:804-11.

27. Koenker H, Kilian A, Zegers de Beyl C, Onyefunafoa EO, Selby RA, Abeku $\mathrm{T}$, et al. What happens to lost nets: a multi-country analysis of reasons for LLIN attrition using 14 household surveys in four countries. Malar J. 2014;13:464.

28. Graves PM, Richards FO, Ngondi J, Emerson PM, Shargie EB, Endeshaw $T$, et al. Individual, household and environmental risk factors for malaria infection in Amhara, Oromia and SNNP regions of Ethiopia. Trans R Soc Trop Med Hyg. 2009;103:1211-20.

29. West PA, Protopopoff N, Rowland M, Cumming E, Rand A, Drakeley C, et al. Malaria risk factors in North West Tanzania: the effect of spraying, nets and wealth. PLoS ONE. 2013;8:e65787. 
30. Essendi WM, Vardo-Zalik AM, Lo E, Machani MG, Zhou G, Githeko AK, et al. Epidemiological risk factors for clinical malaria infection in the highlands of Western Kenya. Malar J. 2019;18:211.

31. Mmbando BP, Vestergaard LS, Kitua AY, Lemnge MM, Theander TG, Lusingu JP. A progressive declining in the burden of malaria in northeastern Tanzania. Malar J. 2010;9:216.

32. Bødker R, Akida J, Shayo D, Kisinza W, Msangeni HA, Pedersen EM, et al. Relationship between altitude and intensity of malaria transmission in the Usambara Mountains. Tanzania J Med Entomol. 2003:40:706-17.

33. Lwetoijera DW, Kiware SS, Mageni ZD, Dongus S, Harris C, Devine GJ, et al. A need for better housing to further reduce indoor malaria transmission in areas with high bed net coverage. Parasit Vectors. 2013;6:57.

34. Tusting LS, Ippolito MM, Willey BA, Kleinschmidt I, Dorsey G, Gosling RD, et al. The evidence for improving housing to reduce malaria: a systematic review and meta-analysis. Malar J. 2015;14:209.

35. Lindsay SW, Jawara M, Paine K, Pinder M, Walraven GEL, Emerson PM. Changes in house design reduce exposure to malaria mosquitoes. Trop Med Int Health. 2003;8:512-7.

36. Winskill P, Rowland M, Mtove G, Malima RC, Kirby MJ. Malaria risk factors in north-east Tanzania. Malar J. 2011:10:98.
37. Noor AM, Kirui VC, Brooker SJ, Snow RW. The use of insecticide treated nets by age: implications for universal coverage in Africa. BMC Public Health. 2009;9:369.

38. Nankabirwa J, Brooker SJ, Clarke SE, Fernando D, Gitonga CW, Schellenberg D, et al. Malaria in school-age children in Africa: an increasingly important challenge. Trop Med Int Health. 2014;19:1294-309.

39. Mayagaya VS, Nkwengulila G, Lyimo IN, Kihonda J, Mtambala H, Ngonyan $\mathrm{H}$, et al. The impact of livestock on the abundance, resting behaviour and sporozoite rate of malaria vectors in southern Tanzania. Malar J. 2015;21(14):17.

40. Kitau J, Oxborough RM, Tungu PK, Matowo J, Malima RC, Magesa SM, et al. Species shifts in the Anopheles gambiae complex: do LLINs successfully control Anopheles arabiensis? PLoS ONE. 2012;7:e31481.

\section{Publisher's Note}

Springer Nature remains neutral with regard to jurisdictional claims in published maps and institutional affiliations.
Ready to submit your research? Choose BMC and benefit from:

- fast, convenient online submission

- thorough peer review by experienced researchers in your field

- rapid publication on acceptance

- support for research data, including large and complex data types

- gold Open Access which fosters wider collaboration and increased citations

- maximum visibility for your research: over $100 \mathrm{M}$ website views per year

At BMC, research is always in progress.

Learn more biomedcentral.com/submissions 